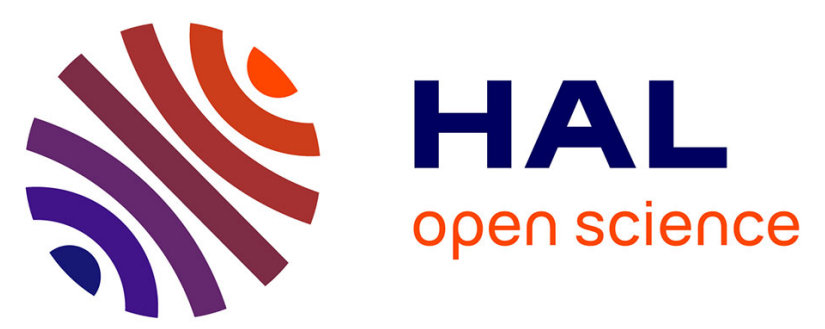

\title{
Interplay of Requirements Engineering and Human Computer Interaction Approaches in the Evolution of a Mobile Agriculture Information System
}

\author{
Lasanthi De Silva, Tamara Ginige, Pasquale Di Giovanni, Maneesh Mathai, \\ Jeevani Goonetillake, Gihan Wikramanayake, Monica Sebillo, Giuliana \\ Vitiello, Genoveffa Tortora, Maurizio Tucci, et al.
}

\section{To cite this version:}

Lasanthi De Silva, Tamara Ginige, Pasquale Di Giovanni, Maneesh Mathai, Jeevani Goonetillake, et al.. Interplay of Requirements Engineering and Human Computer Interaction Approaches in the Evolution of a Mobile Agriculture Information System. 1st and 2nd International Workshop on Usabilityand Accessibility-Focused Requirements Engineering (UsARE 2012 / UsARE 2014), Jun 2012, Zurich, Switzerland. pp.135-159, 10.1007/978-3-319-45916-5_9. hal-01631310

\author{
HAL Id: hal-01631310 \\ https://hal.inria.fr/hal-01631310
}

Submitted on 9 Nov 2017

HAL is a multi-disciplinary open access archive for the deposit and dissemination of scientific research documents, whether they are published or not. The documents may come from teaching and research institutions in France or abroad, or from public or private research centers.
L'archive ouverte pluridisciplinaire HAL, est destinée au dépôt et à la diffusion de documents scientifiques de niveau recherche, publiés ou non, émanant des établissements d'enseignement et de recherche français ou étrangers, des laboratoires publics ou privés. 


\title{
Interplay of Requirements Engineering and Human Computer Interaction approaches in the Evolution of a Mobile Agriculture Information System
}

\author{
Lasanthi De Silva ${ }^{1}$, Tamara Ginige ${ }^{3}$, Pasquale Di Giovanni ${ }^{4}$, Maneesh Mathai ${ }^{2}$, \\ JeevaniGoonetillake ${ }^{1}$, Gihan Wikramanayake ${ }^{1}$, Monica Sebillo ${ }^{4}$, Giuliana Vitiello ${ }^{4}$, \\ Genoveffa Tortora ${ }^{4}$, Maurizio Tucci ${ }^{4}$, Athula Ginige ${ }^{2}$ \\ ${ }^{1}$ University of Colombo School of Computing, Colombo, Sri Lanka \\ \{lnc, jsg, gnw $@$ aucsc.cmb.ac.lk \\ ${ }^{2}$ Western Sydney University Sydney, Australia \\ \{A.Ginige, M.Mathai \} @westernsydney.edu.au \\ ${ }^{3}$ School of Business, Australian Catholic University Sydney, Australia \\ Tamara.Ginigedacu.edu.au \\ ${ }^{4}$ University of Salerno Italy \\ \{msebillo, gvitiello, tortora, mtucci,pdigiovanni\}@unisa.it
}

\begin{abstract}
Very high adoption of mobile phones in developing countries can be used to empower people engaged in various sectors such as agriculture, fisheries and healthcare by providing timely information in right context, thus facilitating them to make informed decisions. Having identified lack of such information is badly affecting farmers in Sri Lanka we embarked on a project to develop a mobile based agriculture information system. We had to combine different theories and methods both from Requirements Engineering (RE) and Human Computer Interaction (HCI) on a need basis to successfully gather the requirements. When we retraced the process we saw a definitive systematic pattern as to how RE and HCI can be used to enrich such an artefact; highlighting the strong interplay between RE and HCI. Discovery of this pattern enabled us to generalise the process.
\end{abstract}

Keywords: Requirement Engineering, Human Computer Interaction. Mobile Agriculture Information System, ICT for Development

\section{Introduction}

Timely access to necessary information is essential to make informed decisions. With mobiles the ability to access information without being limited in terms of time of the day and location has vastly improved. The myriads of in-build sensors in mobiles such as GPS, Camera, microphone etc. open-up new possibilities to develop next generation of social networks known as Social Life Networks [1]. These not only connect people to people, but also have the capability of providing real-time, context- 
sensitive local information by aggregating information from a variety of sources including SMS messages, sensor data and data from public sources [2, 3].

Today the mobile has become the most popular and common way of communication among people worldwide [4, 5]. According to International Telecommunication Union (ITU) by end of 2015 there were nearly 7 billion mobile-cellular subscriptions worldwide. In terms of users there were 3.2 billion people using the Internet which is around, $51 \%$ of the total world population. For every Internet user in the developed world there were 2 in the developing world [6]. Mobile broadband is the most dynamic market segment; globally, mobile broadband penetration is expected to reach $47 \%$ in 2015, a value that increased 12 times since 2007 [6]. Thus, the significant growth of mobiles and use of the internet, especially in developing countries have opened up new possibilities to find effective ways to provide information related to livelihood activities of these people.

Yet there are not that many applications to support information needs related to livelihood activities of people working in sectors such as agriculture, fisheries, healthcare and education in developing countries. Due to lack of such information they face difficulties in their livelihood activities as they are unable to make informed decisions. It is now technically possible to develop mobile based information systems to aggregate real time information on evolving situations such as demand, current levels of production, spread of pests and diseases in crops and natural disasters to provide just-in-time assistance and support for these people to make informed decisions [7].

Inspired by the potentials and capabilities of the mobile technology, we an international collaborative research team, embarked on a project to explore potential mobile based applications to assist people in the developing world. The research team consists of researchers from four countries in four continents; Sri Lanka, Australia, Italy and USA [2]. We carried out field visits, information gathering meetings, industry round table discussions, workshops and brainstorming sessions to identify the potential mobile based applications. During these discussions it came to our attention a persistent vegetable over-production problem in Sri Lanka [8-16]. The issue was almost all the farmers tend to grow the same crop at the same time creating an oversupply situation. This in return creates a drastic impact on the farmers' revenue $[9,10$, $14,16,17]$.

Crop diversification can resolve this issue. At the time of selecting a crop to grow, farmers need to know the current production level of that crop. This information would help them to select a crop that is not in high production, hence avoiding a possible over production situation. This requires farmers sharing what they are planning to grow, aggregating this information and providing the aggregated production levels back to the farmers. This scenario is an example of how timely information in right context can enhance informed decision making. Thus, we selected the agriculture domain to explore how we can develop a mobile based information system to enhance flow of information to facilitate informed decision making.

The development of this mobile application requires identifying the information needs and deciding on the system functionality (Requirement Engineering - RE) to deliver the information to user in an effective way (Human Computer Interaction - 
HCI). The identification of the system functionalities requires better understanding of the application domain and their requirements. Usability is defined as the degree to which a product or system can be used by specified users to achieve specified goals with effectiveness, efficiency and satisfaction in a specified context of use [18]. This in turn reshapes the functionality and how it is presented to the user to interact with it highlighting the importance of interplay between both RE and HCI in system development.

The development of the mobile agriculture information system using the smartphone technology was a challenge during the initial phases of the research. User novelty to the technology and the unclear system functionalities made the development of the artefact a challenging task. Requirements were difficult to derive as researchers did not have a good understanding of activities specific to agriculture domain and users lacked knowledge about the relevant technologies and its capabilities. Further as the research team members were based in 4 continents, the location of researchers added another layer of complexity.

To develop the artefact presented in this chapter we had to find a process that can help to overcome these challenges. At the end, using a modified version of the Design Science Research (DSR) methodology the researchers succeeded in developing an artefact that met both RE and HCI requirements. Using the development of this mobile agriculture information system, we present the process that evolved and the way both RE and HCI requirements were captured at different stages of the artefact development.

\section{Related Work}

In recent years, a growing number of researchers have identified initially call phones and later smartphones as an ideal platform for developing applications for people in developing countries [19] as these can deliver not only voice but also information [5]. The user group that we were targeting was new to this technology and also had a low literacy level. Thus, we focused our literature review to identify available mobile based artefacts targeted at providing information for similar groups of people. We paid special attention to the approaches that were used in these artefacts to present information to the users.

Mehdi et al. have focused their attention on mobile phones as a platform for nonliterate people to access financial services [20]. In particular, they focused on the design of user interfaces for non-literate and semi-literate users. They have observed that non-literate and semi-literate users were unable to make sense of text-based user interfaces (UIs). The task-completion rates were better for the rich multimedia UIs, and when spoken dialog was added to the UIs it further reduced the task completion time and required less assistance.

Danis et al. have observed that in the Sub-Saharan Africa there is on average one doctor for every 20,000 people [21]. This required new health approaches that were focused on prevention rather than treatment. Hence, they analysed two deployments of an SMS-based HIV/AIDS education system that uses a quiz format to assess peo- 
ple's knowledge of the disease, including its causes and methods of prevention. In particular they first focused on the challenges that the use of SMS presented as user interaction mechanism and later explored factors that influenced the participation in quiz games. The paper shows that mobile devices are suitable for this type of activities.

Putnam et al. [22] discusses a case study aimed at identifying user requirements of mobile phone users living in Kyrgyzstan. They used scenarios and personas to better capture the user requirements. They described in their study, how they had transformed these into a set of functional requirements. During the study they developed a working prototype and evaluated the usability.

An extensive study done on the existing mobile applications for agriculture and rural development has shown that countries such as India, Kenya and Uganda are the leading developing countries that use many such mobile applications for agriculture activities [4]. AvaajOtalo (voice stoop) is an interactive voice application developed for small-scale farmers in Gujarat, India [23]. Upon calling a toll-free number farmers are presented an audio menu to select an activity. These activities include question and answer forum to ask questions and listen to answers for similar issues, announcements board, and radio achieve on most popular agriculture radio programs in Gujarat.

eSagu is another advisory service developed for Indian farmers to seek agriculture advice from agriculture experts for different pests and disease found in their farms [24]. Farmer or a coordinator is given the provision to capture images of crop diseases and send these with a corresponding text description seeking advice. They were also required to enter the details about the current status of the soil and weather conditions to provide the farm context. This is a complex task for the farmers and they mostly depend on the agriculture coordinator to enter these values. If there is an error in the provided parameters that then will affect the advice they receive, thus restricting the usefulness of the application.

mKrishi is an agro advisory system designed for rural farmer communities in India to get access to experts living in cities. Farmers can use voice queries and images of insects and disease affected plants to ask for advice from agriculture experts. In this system the farm context is obtained by using sensors to measure parameters such as canopy and ground temperatures as well as data from small weather stations installed in the farms [25].

In Sri Lanka there are two mobile-based applications designed for farmers to obtain agriculture market information; Dialog trade net [26] and 6666 Agri-price index [27]. Both applications are based on voice and SMS. 6666 Agri Price service provide current prices at different markets in collaboration with Hector Kobbakaduwa Agrarian Research and Technology Institute (HARTI). HARTI is the main operating body in Sri Lanka to gather price related information in leading markets. However, the popularity of these services is relatively low among the farmers in Sri Lanka, when compared to similar services in other developing countries.

Table 1 shows the modality, functionalities and the HCI aspects found in the above agriculture related artefacts. 
From the above reviews it is evident that the modality of the existing mobile based artefacts in the agriculture domain is based on basic voice, SMS and image uploading facilities. This presentation mechanism reduces the amount of information provided for the end users. Further, none of the reviewed artefacts has catered for the entire crop life cycle. Most of these artefacts have covered only a sub set of information required by the users. In contrast our main aim was to identify an effective way to provide information for the whole farming life cycle by addressing the above limitations.

Table 1. Modality, Functionalities and HCI Aspects; Agriculture Artefacts

\begin{tabular}{|c|c|c|c|}
\hline Application & Modality & Functionalities (Information) & HCI Aspects \\
\hline Dialog Trade Net & Voice and SMS & Market Prices & No Specific Interface \\
\hline Mobitel 6666 & Voice and SMS & Market Prices & No Specific Interface \\
\hline mKrishi & $\begin{array}{l}\text { Voice and SMS } \\
\text { Image uploading } \\
\text { facility }\end{array}$ & $\begin{array}{l}\text { Agro Advisory on crops, } \\
\text { weather, prices, pest \& } \\
\text { diseases }\end{array}$ & $\begin{array}{l}\text { A standard interface for } \\
\text { SMS and image uploading }\end{array}$ \\
\hline eSagu & $\begin{array}{l}\text { Voice and SMS } \\
\text { Image uploading } \\
\text { facility }\end{array}$ & $\begin{array}{l}\text { Agro Advisory on crops, } \\
\text { weather, prices, pest \& } \\
\text { diseases }\end{array}$ & $\begin{array}{l}\text { A standard interface for } \\
\text { SMS and image uploading }\end{array}$ \\
\hline AvaajOtalo & $\begin{array}{l}\text { Voice and text } \\
\text { input }\end{array}$ & $\begin{array}{l}\text { Question answering on agri } \\
\text { issues, announcements and } \\
\text { radio archive }\end{array}$ & $\begin{array}{l}\text { A menu based interface for } \\
\text { voice and text inputs }\end{array}$ \\
\hline
\end{tabular}

We also reviewed ICT4D and HCI4D literature especially in relation to development process, specific methods and techniques that have been successfully used to develop similar applications. Peter [28] has reported lack of user-centred design due to resource constraints as major cause for high rate of ICTD project failure. He has introduced user persona from UX design as a powerful tool for considering the user's perspective within resource-constrained ICTD projects. Human-computer interaction for development (HCI4D) requires considerable time in the field interacting with users. While this is true for most HCI work, fieldwork in developing regions presents unique challenges due to differences in culture, language, ethnicity, and socioeconomic status. A group of 9 researchers having reflected on their experiences have suggested a mix of qualitative and quantitative instruments to elicit and synthesize individual experiences [29]. Above review indicated the importance of blending multiple approaches to successfully develop applications to support livelihood activities of people in developing countries.

\section{Research Approach}

The main aim of this research project was to design a mobile artefact that will assist farmers in decision making. Artefacts are "innovations that define ideas, practices, technical capabilities, products through which the analysis, design, implementation, 
and use of information systems can be effectively and efficiently accomplished" [30]. The Design Science Research (DSR) methodology is capable of designing an innovative artefact to solve real world problems [30,31]. DSR is a matured growing field which is increasingly used in designing information systems [32-35]. DSR method is capable of making a significant impact on developing information systems as it seeks innovation and creativeness in designing the artefacts. DSR further conducts "applicable, yet rigorous research" [34] to design innovative artefacts. DSR can effectively guide the design of this innovative artefact by facilitating active participation of both researchers and end users. The research process captures the knowledge to guide the researchers to meet the desired outcomes [32]. The development of the artefact aims at achieving the utility of a solution. Thus, in turn it will enhance both efficiency and effectiveness of the artefact.

In 2004, Hevner proposed a generic DSR framework for the researchers who conduct DSR in information systems design [30]. Later in 2007 [33] it was presented as consisting of three cycles; Relevance, Design and Rigor. The relevance cycle identifies the requirements from the contextual environment and input into the research activities. It further introduces artefacts produced as a result of the research activities to the environment for field testing. The rigor cycle provides grounding knowledge to conduct the research activities and adds new knowledge generated as a result of these activities. The design cycle operates within research activities of artefact construction and evaluation. Therefore, these three cycles operate within the contextual environment, design science research activities and knowledgebase as illustrated in Fig. 1. Environment or the application domain is composed of people, organizational systems, technical systems, potential problems and opportunities. Design Science Research activities include building and designing of artefacts to meet the user requirements. The knowledgebase provides the fundamental knowledge using different modalities to ensure design rigor in DSR [33]. Scientific theories and methods, experience and expertise, meta-artefacts are some of the fundamental knowledge sources referred to in designing the artefact.

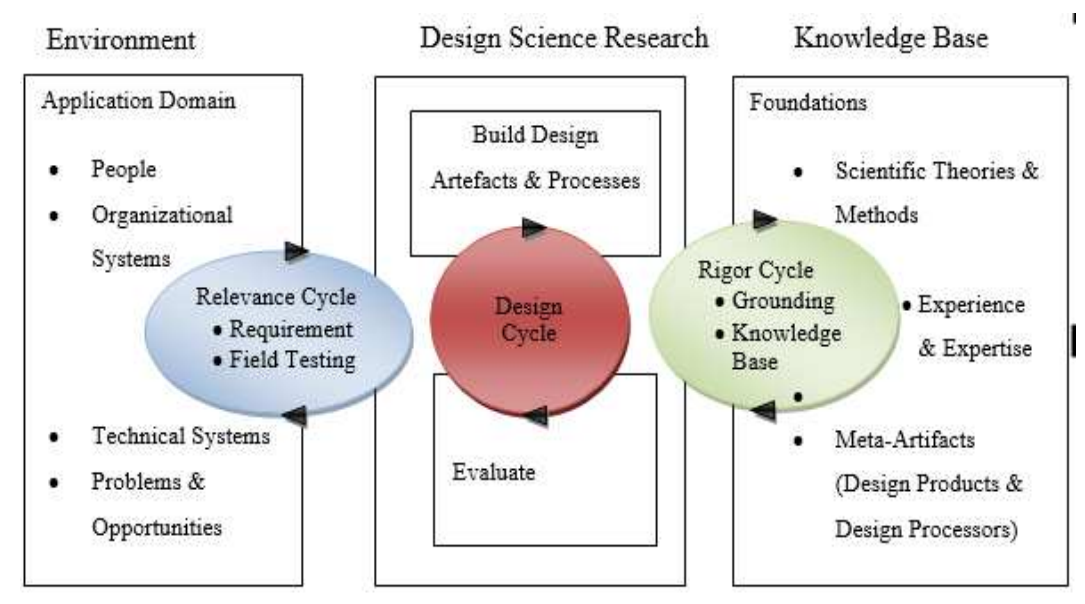

Fig. 1. Traditional DSR Cycles presented in [33] 
To meet the practical aspects of this project we had to modify the traditional DSR cycles. Each DSR cycle is further divided into two sub parts. Splitting of these cycles were required, in order to manage the complexity of the problem domain and also to enable international collaboration as some activities were carried out at different times in different locations. The resultant cycles can be visualised with respect to the three original cycles as explained below.

- Relevance Cycle: The Relevance Cycle bridges the actual environment and the research activities in a DSR project. As stated by Hevner [30] a "good design science research project often begins by identifying and representing opportunities and problems in an actual application environment". Problems and opportunities of the actual application domain could arise from its environment or from outside the environment. Identification of such problems and opportunities is essential to provide a new and innovative artefact [33]. Based on the observations Relevance Cycle was divided into two sub cycles. These were named as Relevance -Problem Understanding (RePU) and Relevance - Suitability Validation (ReSV). While RePU gathers requirements to understand the problem, ReSV check the suitability of the artefact using field validation. This split was needed as these activities happened at two different times.

- Design Cycle: The Design Cycle is the "heart" of any design science research project [33]. It iterates within the design, construction of the artefacts and its functional validation until a satisfactory design is achieved. Most of the hard work is carried out within this cycle before producing an artefact for field testing. Design cycle performs two main activities in relation to producing a good, efficient artefact. Two main sub parts in Design Cycle are Heuristic search $(\mathrm{DeHS})$ and Functional validation $(D e F V)$. In DeHS a design that can meet immediate goals is identified, designed and constructed. DeHS applies various heuristic search methods to create a good artefact. The constructed artefact is evaluated to ensure its functional correctness in DeFV. The designer iterates between DeHS and DeFV until the artefact is free of functional errors. This split was needed as these activities happened at different times and took place in different locations.

- Rigor Cycle: The Rigor Cycle provides grounding theories and methods along with domain experience and expertise from the foundations knowledge base into the research and adds the new knowledge generated by the research to the growing knowledge base [33]. First the relevant prior knowledge is identified to ground the design of the new artefact as well as to identify any gaps that may exist in relation to the requirements that the new artefact should satisfy. This ensures that the research is conducted in a rigorous manner and assists to clearly identify the innovation aspects of the solution. The new knowledge generated in this process is contributed back to the knowledge base for use of future researchers. The rigor cycle can be represented as learning's from the existing or grounding knowledge and contributions as new knowledge. Thus, Rigor Cycle can be divided into two sub cycles; Learning from the grounding knowledge (RiLe) and Contributions back to the knowledge base (RiCo). This split was needed as these activities happened at different times in different locations. 
Fig. 2 shows the split DSR model overlaid on the original 3 cycle model. Naming convention of the new cycles is given in Table 2 .

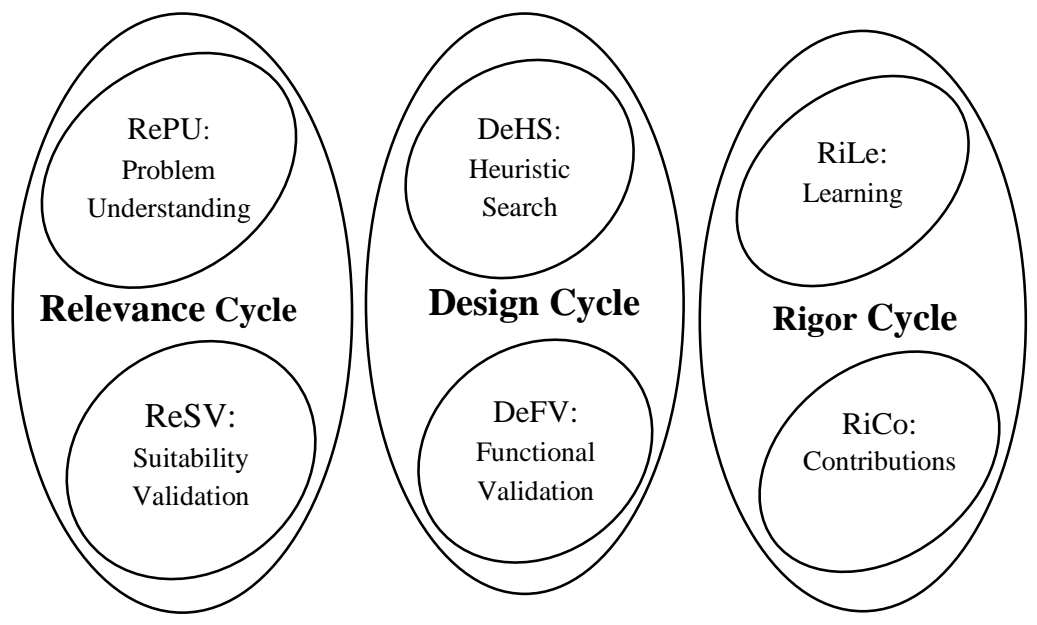

Fig. 2. Split DSR Model

Table 2. Naming convention of the cycles in the split DSR model

\begin{tabular}{|l|l|}
\hline Abbreviation & Corresponding DSR Cycle Naming \\
\hline RePU & Relevance - Problem Understanding Cycle \\
\hline ReSV & Relevance - Suitability Validation Cycle \\
\hline DeHS & Design - Heuristic Search Cycle \\
\hline DeFV & Design - Functional Validation Cycle \\
\hline RiLe & Rigor - Learning Cycle \\
\hline RiCo & Rigor - Contributions Cycle \\
\hline
\end{tabular}

\section{Evolution of the Agriculture Mobile Information System}

To develop the agriculture mobile information system we iterated through these six (06) sub cycles of the Split DSR model shown in figure 2. As we have used these sub cycles multiple times we assigned a number for each use to clearly distinguish the sub cycles; i.e. RePU1, DeHS1..etc, The initial discussion described in the introduction triggered the Relevance - Problem Understanding sub cycle (RePU1) to gather domain knowledge relevant to vegetable over production issues faced by the farming communities in Sri Lanka. We needed to develop an understanding of the problem domain to be able to identify the required system functionalities. For this we investigated the problem domain using interviews and survey questionnaires involving farmers and agriculture officers. Initial surveys were designed to find out what farmers thought of the cause for over production and actions that they take to mitigate this 
issue. We discovered that some farmers were estimating current production levels by talking to seed suppliers to find out quantities of seeds that have been purchased so far. We identified that this was not an effective approach because there were many seed suppliers. Also some farmers were producing seeds for their own use as well as to sell to others. This made it difficult to get a realistic aggregated value for current production level of a crop based on amount of seeds being sold. This led us to explore the possibility of sharing production quantities via the mobile technology to derive an aggregated value.

Even with these findings and domain understanding the researchers only had a vague idea on the exact user requirements to design the artefact. Therefore, using the data collected we decided to create personas and scenarios to better understand the domain and derive user requirements [22].

\subsection{Scenarios for the User Domain}

The knowledge gained from RePU1cycle led us to create a scenario of truck farming (or large scale commercial farming) practices that triggered a Design - Heuristic Search sub cycle (DeHS1). The scenario formed a base for brainstorming and discussion of initial requirements. Based on information gathered so far, we defined two personas, representing possible stakeholders as shown below.

\footnotetext{
Actors

1. Sirisena is a 45 years old farmer with long experience in truck farming. Sirisena is part of Sinhalese ethnic group. He has a basic education level; he attended the primary school, he can read and write Sinhalese and he has a basic knowledge of English. Sirisena does not have advanced technical skills, the only technological instrument is his mobile phone that he uses every day. Moreover he is pretty distrustful of the technological support and, during his work, is accustomed to rely on his farmer experience. Sirisena lives in Sigiriya, a village in the central Matale District of Sri Lanka, where he owns four acres of farm land. Since the property is quite large, Sirisena in his work is supported by eight collaborators. Since Sirisena has a long experience in truck farming he manages the crop production of his family farm. His role is to make decisions on critical aspects of the production. He takes decisions on the kind of production and the time to start it. Moreover he establishes an indicative selling price.

2. Premasiri is a 40 years old low price fertilizers seller. Like Sirisena, Premasiri is part of the Sinhalese ethnic group and lives near Sigiriya. In order to raise his revenues he also acts as market middle man. Since he can speak English as good as Sinhalese and has a basic knowledge of Tamil, his intermediary role is well recognized by the farmers of the area. During the market activities his responsibility is to negotiate the best selling price of the product trying to match the expectations of his clients.
}

Scenarios

Sirisena manages the crop production of the farm

Sirisena is planning the new crop production. The decision will be made on the basis of three factors.

He takes in to account: 


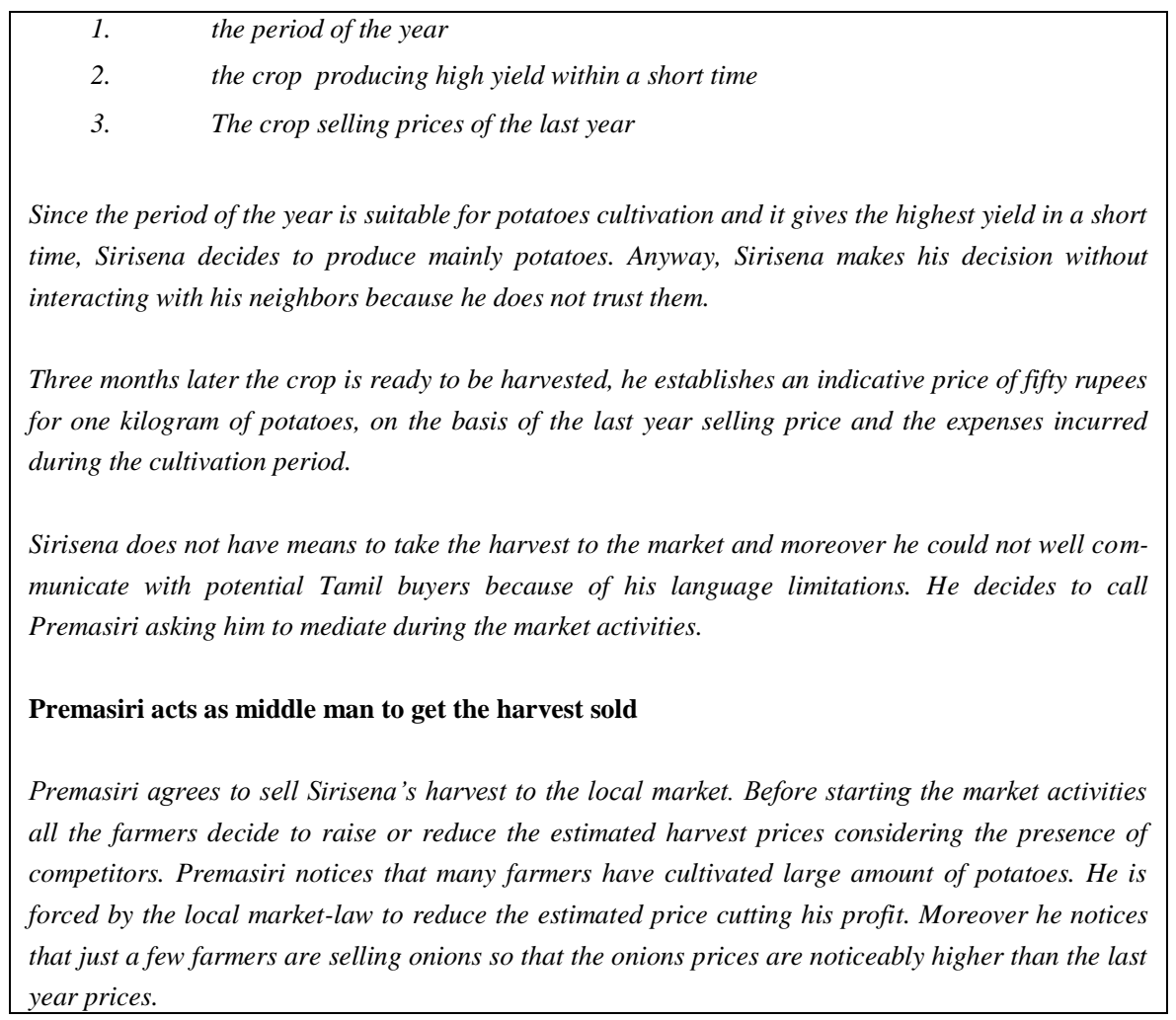

User scenarios were then transformed to identify the design claims of the artefact. The scenarios, design claims and application requirements were used to derive a list of interface requirements for the end users considering literacy, familiarity in using a mobile device, users' cultural background and language beliefs. Further information on the scenarios, design claims and requirements can be found in [36]. These led us in identifying some core system functionalities and initial guidelines for designing the interfaces. Based on the findings we developed the first set of mobile interfaces.

\subsection{The First set of Mobile Interfaces}

The first set of mobile interfaces is shown in 3. The first screen (on the left) represented a crop catalogue. We used icons to describe crops and a coloured background to indicate the approximate quantity of each crop already in production. We used 3 colours; white yellow and red, indicating zero, moderate and intensive production respectively. After selecting a crop, users can navigate to the interface shown in the $2^{\text {nd }}$ screen (on the right) to obtain a more detailed description of the product. We provided radio buttons to insert quantity of crop(s) that they want to cultivate. This minimised typing errors. This input information can be aggregated to derive the current production levels in real time. 
As can be seen from rest of the paper these interfaces started to act as a focal point for the whole research team to coordinate their individual research efforts towards the overall goal. It also gave the whole research team initial glimpse of how information can be communicated via colours on a mobile interface to make best use of available screen area and effectively capture user input.
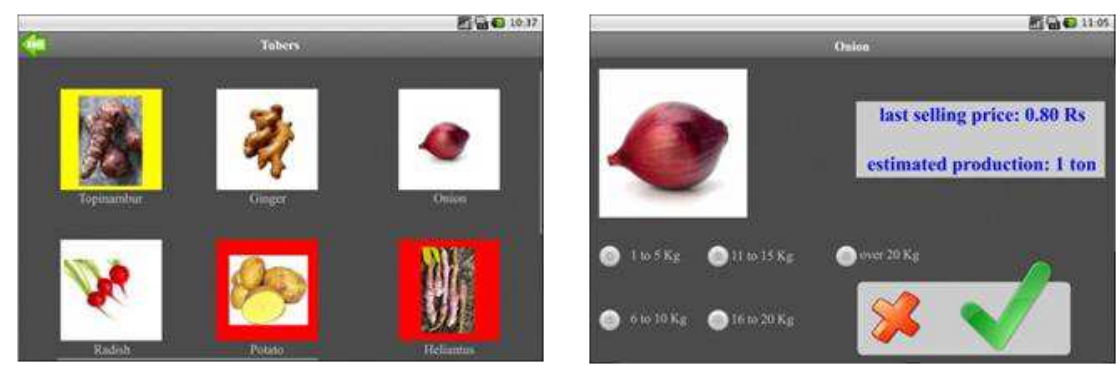

Fig. 3. First Mobile Sketches of the Interfaces

These mock-ups triggered a Relevance -Suitability Validation sub cycle (ReSV1). The mock-ups were shown to group of farmers and Agriculture extension officers to obtain their feedback. We needed to find out their reactions to our design and whether the information is sufficient for them to make an informed decision on selecting crops(s) for a new season.

This iteration through ReSV1 cycle highlighted some HCI issues and triggered a Design- Heuristic Search cycle (DeHS2) to make changes to the interfaces. One such refinement was to change the colour coding scheme to reflect the traffic light colour scheme (green, yellow and red). Users were familiar with traffic light colour scheme and able to interpret overproduction data with this visual message better. We also modified the user interfaces to present many crops under different categories on the mobile interface as shown in Fig 4.

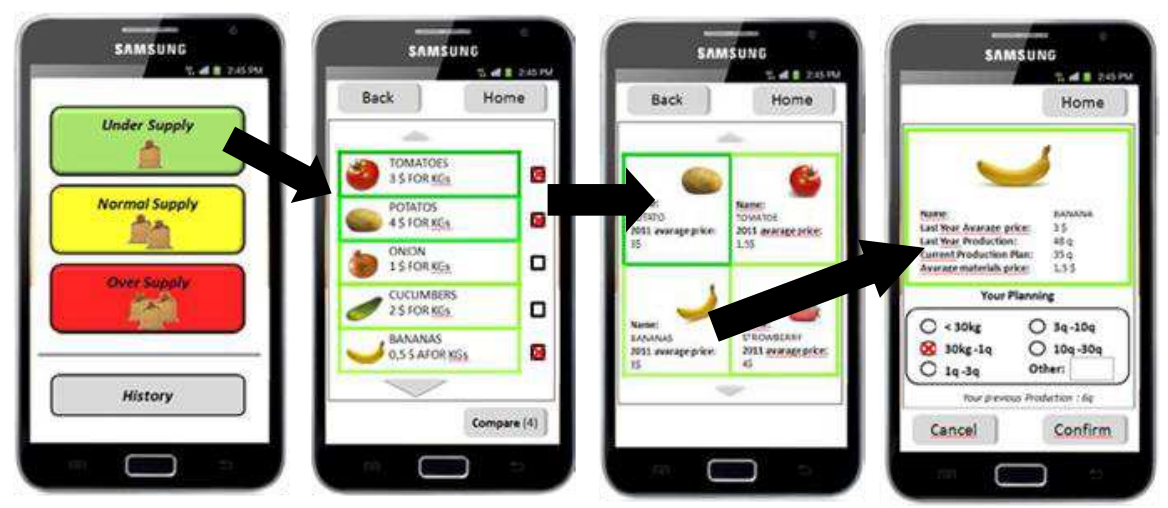

Fig. 4. Modified user interfaces to better visualise the crop catalogue 
In the ReSV1 cycle we also identified that in addition to the aggregated information on production levels, there were other factors that influenced farmers' decision when selecting crop(s) to grow in the next season. This triggered RePU2; a Relevance - Problem Understanding cycle, where we analysed information received from the agriculture officers and collected from newspaper articles in addition to information already collected to create the initial scenarios to identify factors that influence farmer's decision making. As a result, we developed the causal map shown in Fig. 5. From the causal map we were able to identify that the farmers' decision making depends on various factors depending on the stage of the farming life cycle [37]. These insights led the researchers to further learn about information needs of farmers and ways to organize the information.

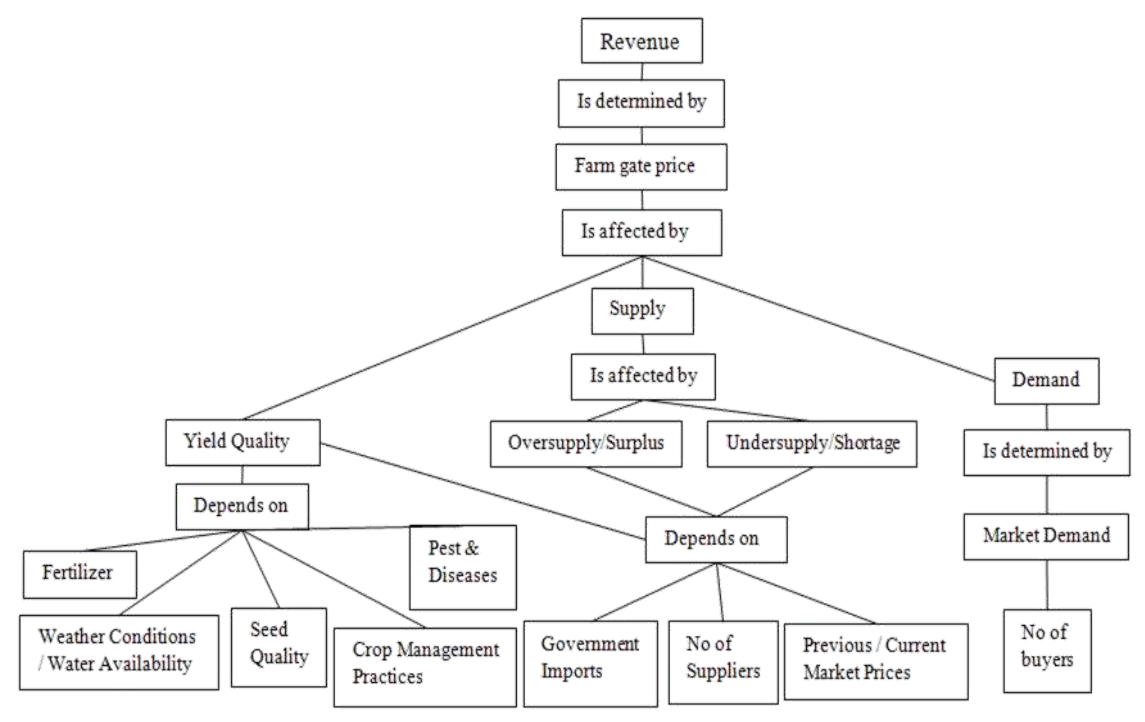

Fig. 5. Causal Map

At this point we conducted a Rigor - Learning (RiLe1) sub cycle to learn about agriculture related information. We identified the possibility of categorising different information needs of farmers to different stages of the farming life cycle. We further identified the need for personalised information to suit different farmers. This led us to think about user context and a farmer registration system to be able to provide contextualised information. Thus, we identified the need for a farmer registration function as shown in Fig. 6. 

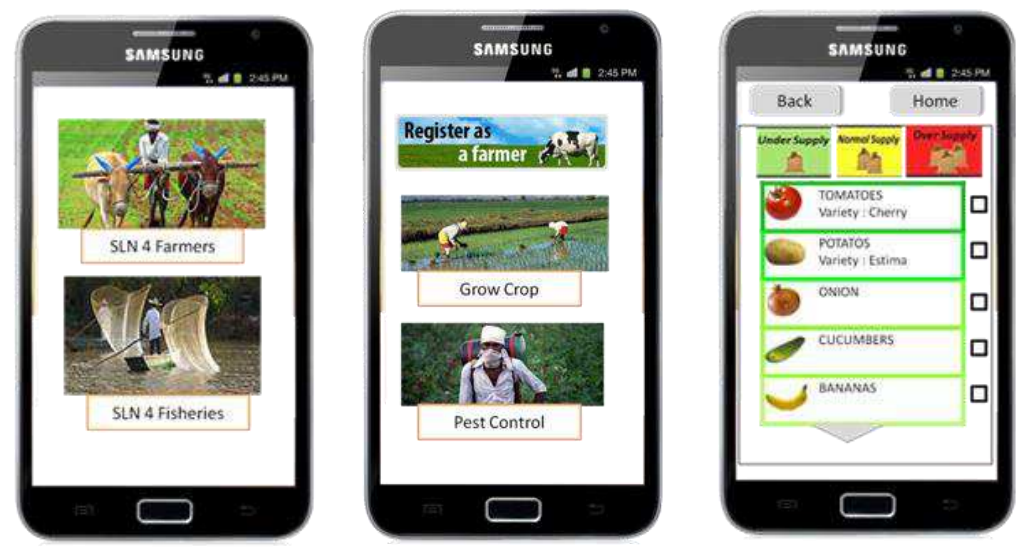

Fig. 6. New user interface mock-ups to provide farmers with contextualised information

\subsection{Paper Prototype Design}

The farming life cycle composes of 6 main stages: Crop planning, seeding, planting, growing, harvesting and selling [38]. Initially, we targeted one stage of the farming life cycle to design the artefact; crop planning. By now we have realised trying to provide information to support all stages of the farming life cycle is a complex task and a practical way to manage this complexity was to design one stage at a time.

Table 3. Tasks, User Actions and System Response for 'Crop Selection'

\begin{tabular}{|c|c|c|}
\hline Task & User Action & System Response \\
\hline \multirow[t]{2}{*}{$\begin{array}{l}\text { A) Suitable crops for } \\
\text { the location }\end{array}$} & Location Check & $\begin{array}{l}\text { List the suitable crops based on the } \\
\text { location of the farmer. }\end{array}$ \\
\hline & $\begin{array}{l}\text { Crop category (Vegetables, Fruits } \\
\text { or other) }\end{array}$ & $\begin{array}{l}\text { List crops based on the crop category } \\
\text { (Vegetables, Fruits or other) }\end{array}$ \\
\hline \multirow{4}{*}{$\begin{array}{l}\text { B) Relevant crop } \\
\text { varieties }\end{array}$} & Crop Selection & Select a crop form the crop list \\
\hline & Variety List & Display varieties of the selected crop \\
\hline & $\begin{array}{l}\text { Check variety specific characteris- } \\
\text { tic }\end{array}$ & $\begin{array}{l}\text { Display additional information on the } \\
\text { selected variety. }\end{array}$ \\
\hline & Check for seed distributors & Display available seed distributors \\
\hline \multirow{2}{*}{ C) Market price } & Crop Selection & Select a crop form the crop list \\
\hline & Check Price & Display last month/week price \\
\hline \multirow{2}{*}{ D) Seed suppliers } & Crop Selection & Select a crop form the crop list \\
\hline & Check for seed distributors & Display available seed distributors \\
\hline \multirow[b]{2}{*}{$\begin{array}{l}\text { E) Crop management } \\
\text { techniques }\end{array}$} & Crop Selection & Select a crop form the crop list \\
\hline & View additional information & $\begin{array}{l}\text { Display additional information on nurse- } \\
\text { ry management, field establishment } \\
\text { techniques, pest and disease issues etc. }\end{array}$ \\
\hline
\end{tabular}




\begin{tabular}{|l|l|l|}
\hline \multirow{2}{*}{ F) Crop plan } & Crop Selection & Select a crop form the crop list \\
\cline { 2 - 3 } & Crop Planned extent & $\begin{array}{l}\text { Enter the number of acres to be cultivat- } \\
\text { ed }\end{array}$ \\
\hline
\end{tabular}

Based on the requirements derived via iterations through RePU2, DeHS2 and RiLe1, we refined the interfaces of the mobile artefact for the crop planning stage using a Design - Heuristic Search (DeHS3) sub cycle. We identified six main tasks in the crop planning stage. Next, these tasks were further divided into more manageable parts comprised of user actions and system responses as listed in Table 3.
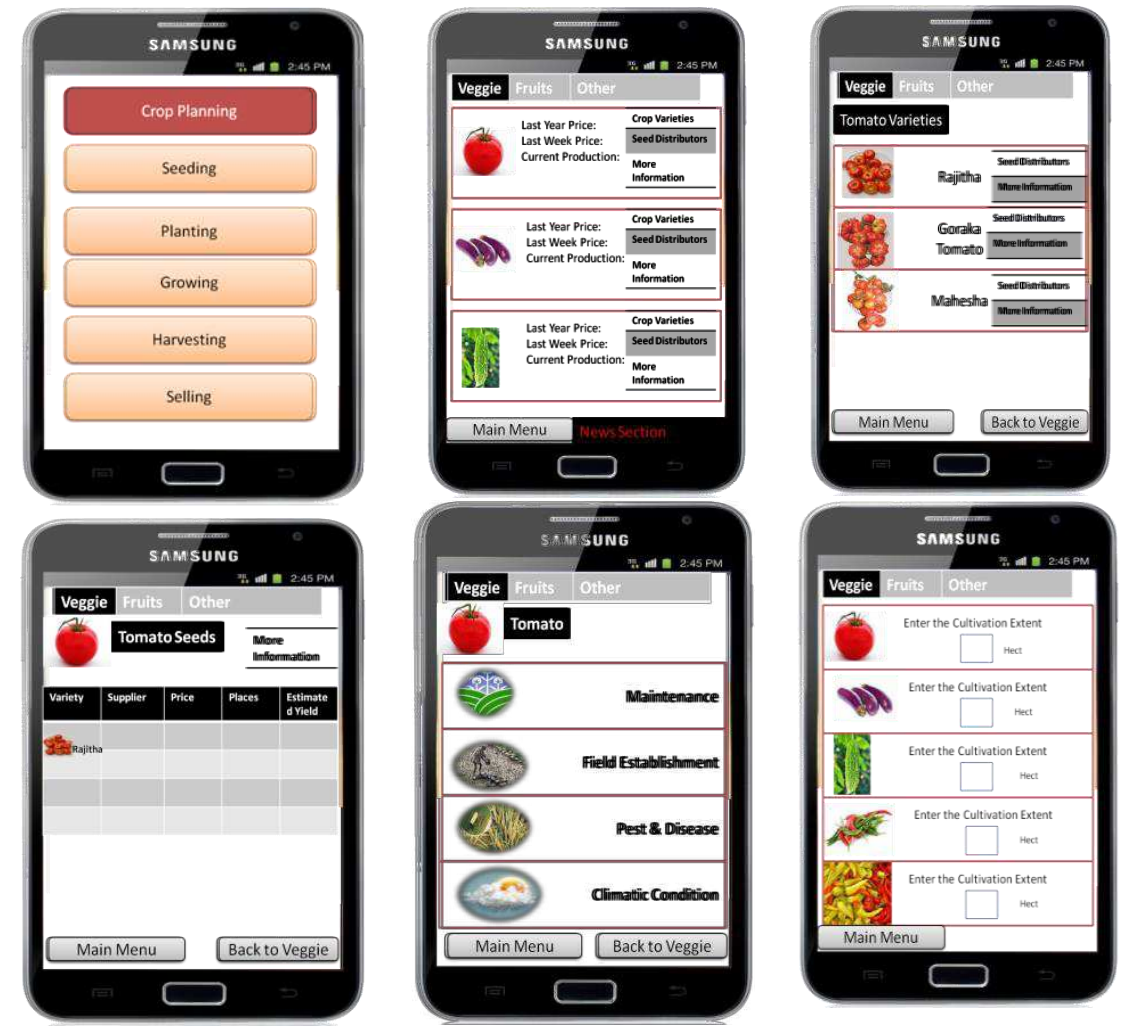

Fig. 7. Designed mobile interfaces for the crop planning stage

During the paper prototype evaluation, farmers were able to see the proposed model (Fig. 7) on paper and it was easier for them to envisage a possible solution. They started to explain their information needs better. In addition they provided us with their feedback on some HCI aspects. Fig. 8 shows some instances when farmers used paper prototypes during this study.

An important observation was the enthusiasm of the farmers in using a smart phone to obtain their daily information needs. Once farmers started see the proposed 
model on paper, they too started to get involved in the design of the artefact. This was evident from the responses and observations made during the interviews. They mentioned that they could see the potential of the proposed solution and expressed the benefits of having this information.
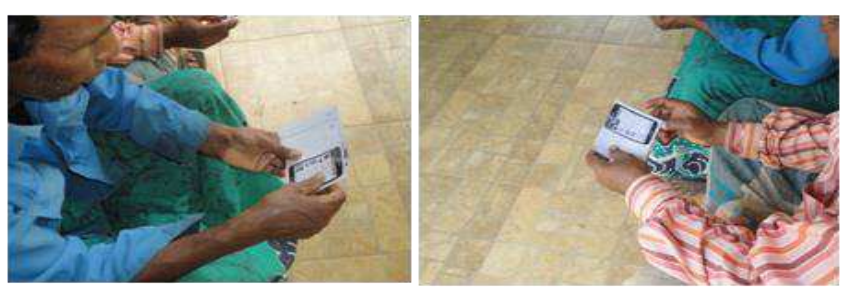

Fig. 8. Farmers evaluating the paper prototype

Table 4. Farmer Information Needs for Crop Selection

\begin{tabular}{|c|c|c|c|c|c|c|}
\hline \multicolumn{2}{|c|}{ Farmer information need } & \multirow{2}{*}{$\begin{array}{l}1 \\
100 \% \\
\end{array}$} & \multirow{2}{*}{$\begin{array}{l}\mathbf{2} \\
0 \%\end{array}$} & \multirow{2}{*}{$\begin{array}{l}\mathbf{3} \\
0 \%\end{array}$} & \multirow{2}{*}{$\begin{array}{l}\mathbf{4} \\
0 \% \\
\end{array}$} & \multirow{2}{*}{$\begin{array}{l}\mathbf{5} \\
0 \% \\
\end{array}$} \\
\hline 1 & Crop Types & & & & & \\
\hline 2 & Last Year Price & $33 \%$ & $40 \%$ & $7 \%$ & $20 \%$ & $0 \%$ \\
\hline 3 & Last Week Price & $33 \%$ & $53 \%$ & $0 \%$ & $13 \%$ & $0 \%$ \\
\hline 4 & Current Production & $80 \%$ & $13 \%$ & $0 \%$ & $0 \%$ & $7 \%$ \\
\hline \multicolumn{7}{|c|}{ Seed/Crop Varieties } \\
\hline 5 & Seed Varieties & $93 \%$ & $7 \%$ & $0 \%$ & $0 \%$ & $0 \%$ \\
\hline 6 & Market Price per variety & $93 \%$ & $7 \%$ & $0 \%$ & $0 \%$ & $0 \%$ \\
\hline 7 & Places to Buy Seeds & $100 \%$ & $0 \%$ & $0 \%$ & $0 \%$ & $0 \%$ \\
\hline 8 & Seed Prices & $93 \%$ & $0 \%$ & $7 \%$ & $0 \%$ & $0 \%$ \\
\hline 9 & Estimated Yield & $7 \%$ & $67 \%$ & $27 \%$ & $0 \%$ & $0 \%$ \\
\hline 10 & Seed Requirement & $7 \%$ & $80 \%$ & $13 \%$ & $0 \%$ & $0 \%$ \\
\hline
\end{tabular}

\begin{tabular}{|c|c|c|c|c|c|c|}
\hline \multicolumn{7}{|c|}{ Information regarding seed varieties } \\
\hline 11 & Colour & $100 \%$ & $0 \%$ & $0 \%$ & $0 \%$ & $0 \%$ \\
\hline 12 & Weight/Harvest & $100 \%$ & $0 \%$ & $0 \%$ & $0 \%$ & $0 \%$ \\
\hline 13 & Quantity & $100 \%$ & $0 \%$ & $0 \%$ & $0 \%$ & $0 \%$ \\
\hline 14 & Special Qualities & $100 \%$ & $0 \%$ & $0 \%$ & $0 \%$ & $0 \%$ \\
\hline 15 & Transportation & $100 \%$ & $0 \%$ & $0 \%$ & $0 \%$ & $0 \%$ \\
\hline 16 & Pest \& Diseases outbreak & $100 \%$ & $0 \%$ & $0 \%$ & $0 \%$ & $0 \%$ \\
\hline 17 & Market Demand & $100 \%$ & $0 \%$ & $0 \%$ & $0 \%$ & $0 \%$ \\
\hline \multicolumn{7}{|c|}{ More Information regarding crops } \\
\hline 18 & Field Establishment & $27 \%$ & $60 \%$ & $13 \%$ & $0 \%$ & $0 \%$ \\
\hline
\end{tabular}




\begin{tabular}{lllllll}
\hline $\mathbf{1 9}$ & Possible Pest \& Diseases & $93 \%$ & $7 \%$ & $0 \%$ & $0 \%$ & $0 \%$ \\
\hline $\mathbf{2 0}$ & Climate Requirement & $13 \%$ & $60 \%$ & $20 \%$ & $0 \%$ & $7 \%$ \\
\hline $\mathbf{2 1}$ & Nursery Management & $20 \%$ & $80 \%$ & $0 \%$ & $0 \%$ & $0 \%$ \\
\hline
\end{tabular}

We analysed the importance of the provided information based on the farmer feedback and rankings. In table 4 we have highlighted the most important information for the crop selection stage. The results of this study triggered another Design - Heuristic Search sub cycle (DeHS4) to refine the interfaces. Refined interfaces are shown in Fig. 9.

In order to satisfy the new information needs of the farmers, it became necessary to find potential sources for this information. Currently, this information is scattered within the agriculture domain. Different stakeholders create this information as a result of their routine activities. This made us realise the importance of developing a properly structured agriculture information repository [39]. Until that was implemented, we decided to use test information to continue designing the mobile prototype.
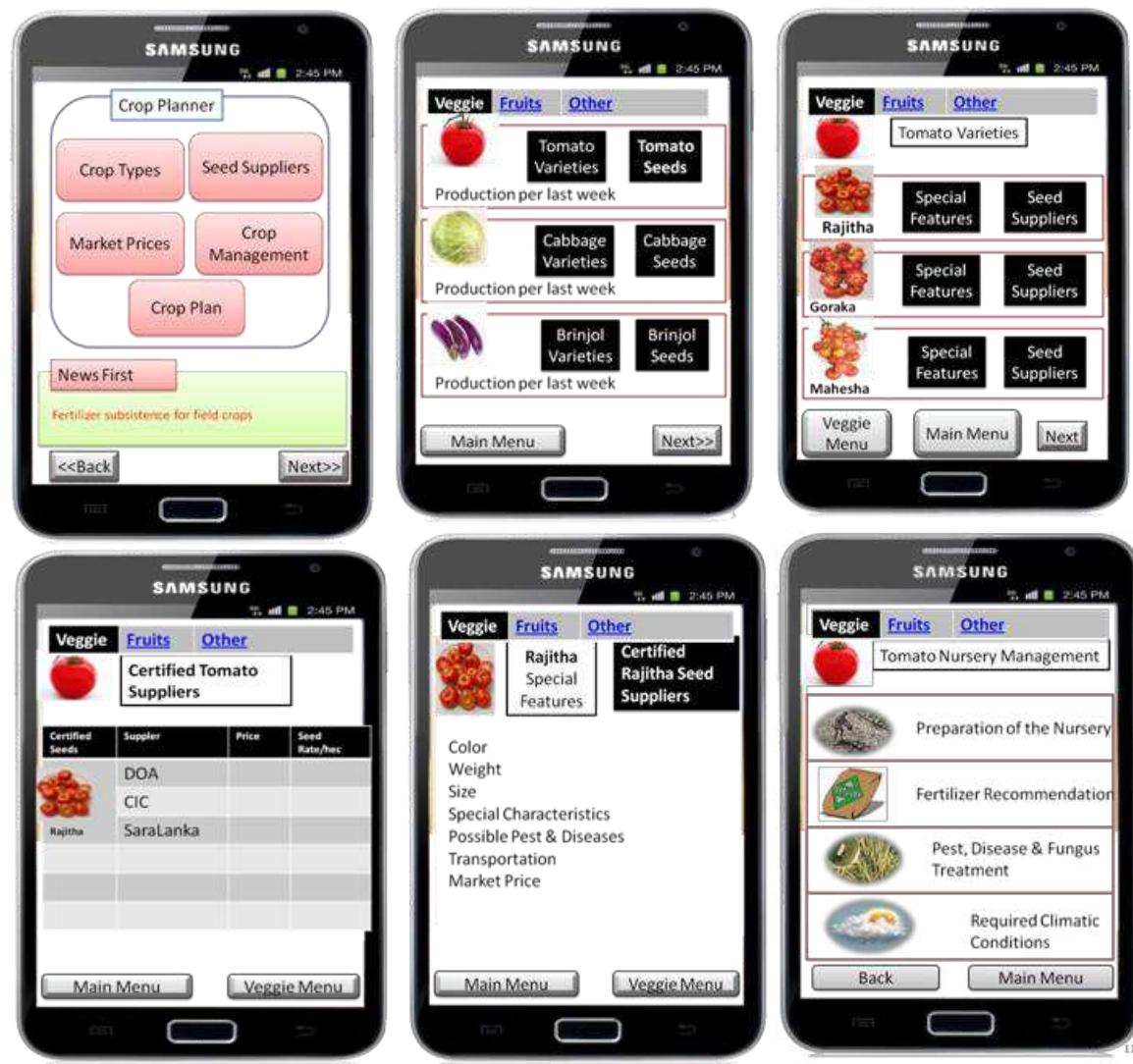

Fig. 9. Refined interfaces based on the comments received from the farmers 


\subsection{First Physical Implementation of the Mobile Artefact}

We implemented a mobile prototype having following functionalities derived from combining insights gained so far, using a Design - Heuristic Search (DeHS5) sub cycle.

- Basic Login Facility: This was used to identify the farmer to provide contextualised information.

- Crop Planner: After a successful login farmer is directed to the crop planner interface, where crops and varieties were categorised in to three main tabs; Vegetables, Fruits and other. A colour coding scheme is used to visually represent the current production level of a crop as shown in Fig. 10. Specific colours are used to represent different thresholds. For example, the colour red is used to specify a threshold that will lead to an oversupply. Once the farmer selects a specific crop variety, it shows special characteristics of that variety such as yield colour, weight, length/size etc. Moreover, it also displays useful statistics such as current production and last year production for the selected crop variety. The application also provides a function for the farmer to view the history of their past activities and a mechanism to compare details of two or more crops.

- Profit Calculator: Profit calculator is designed to help farmers to calculate their farming expenses.
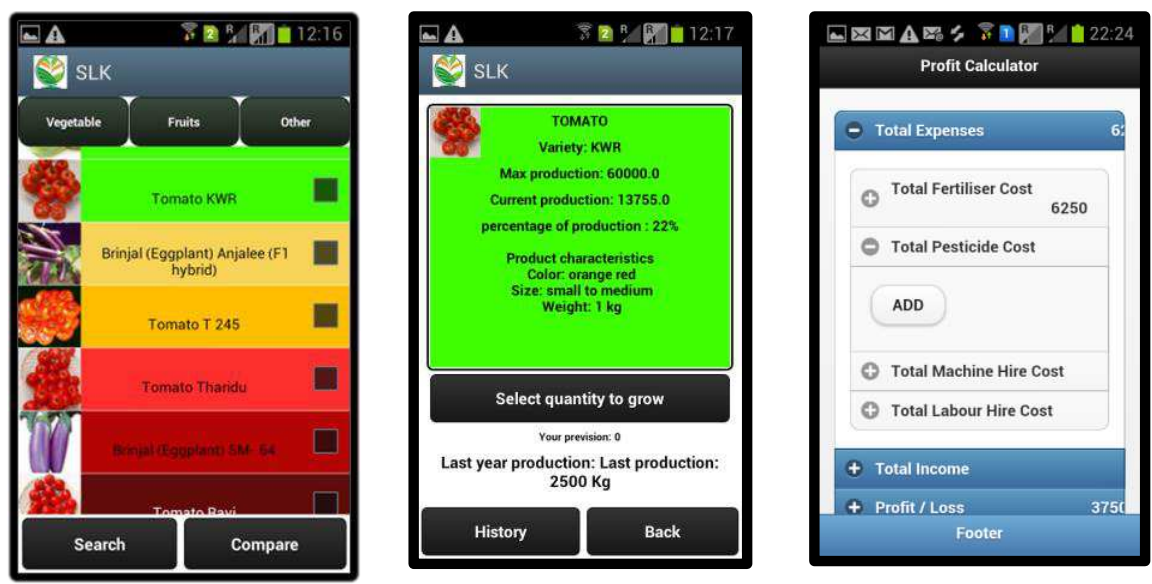

Fig. 10. First Physical Implementation of the Mobile Artefact

This was immediately followed by a Design - Functional Validation DeFV1 sub cycle to perform an internal validation of the implemented functions. This was done by all members of the research team. They tested the functions and any errors that were found were reported to the developers to rectify these.

Next we tested this mobile prototype to validate the suitability of the artefact using a Relevance - Suitability Validation (ReSV3) sub cycle. For this validation a sample of 32 farmers was used. The research instruments used in this validation were the 
working mobile prototype and a questionnaire to record the feedback from the farmers. This was the first hands-on experience of the farmers using the mobile artefact. Out of the 32 farmers, $94 \%$ of them were new to smart phones. However, almost all the farmers got used to the technology within 5-10 minutes. They were asked to perform some tasks related to the farming using the developed application. Fig. 11 shows how the farmers interacted using the mobile application during the field validation. Details of this field trial and findings were reported in [40] which is an example of a Rigor - Contribution (RiCo) sub cycle. In this chapter Rigor - Contribution sub cycles are not numbered as these don't form part of the main process but take place from time to time when there are new insights to be contributed back to the scientific knowledge base.
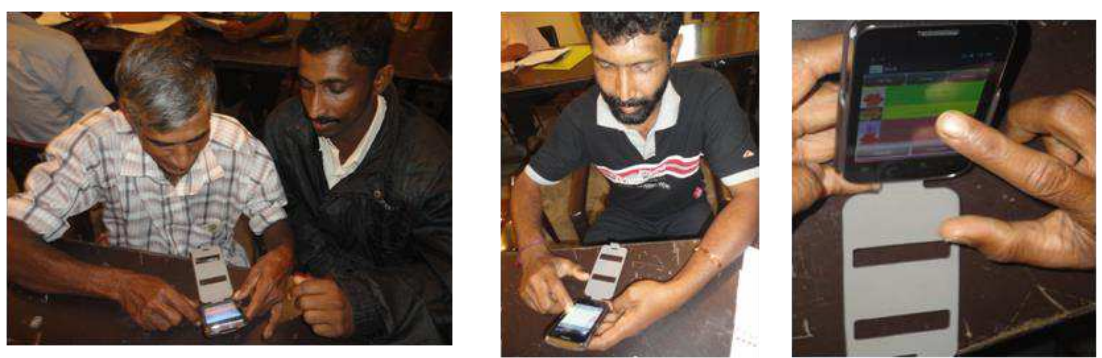

Fig. 11. The farmers using the mobile application during the field validation

The field validation of the first working mobile prototype highlighted the following aspects in three key areas.

- User reaction towards technology: Farmers adapted to the smart phone in few minutes even though they did not have much previous experience with the technology. After the training period they all got used to the application and performed set of tasks defined by the researchers. Farmer reaction towards the technology was positive and all agreed the importance of having such a system to obtain required information. They also mentioned the significance of identifying innovative solutions towards educating young farmers.

- Usability Evaluation: We observed some interface issues when farmers started using the application. Some farmers experienced difficulties in touch due to the size of their fingers and roughness. Some experienced difficulties in touching the buttons due to small space between the buttons. Further, some found it difficult to navigate from one screen to another due to inadequate wordings and onscreen instructions.

- Information correctness: Farmers stressed the need to have accurate, complete and up to date information if they were to rely on the system for better decision making. Further, when they started using the system they felt the usefulness and started to request more functionality.

The ReSV3 sub cycle again demonstrated the potential to obtaining more complete user requirements using user centred iterative process. Though we started with un- 
clear functional requirements, through this iterative process we were able to obtain a complete set of user requirements for the artefact. Moreover, at the initial stages we followed very few HCI guidelines in our design. However, at this stage we have become very aware of the HCI aspects of the users based on our observations during field trials. Though not much HCI requirements came to light during the initial stages of the DSR, latter interactions using the actual working artefact, HCI requirements started to dominate the artefact design.

The findings highlighted the need to concentrate more on the HCI side of the artefact at this stage of the development and provide more complete, accurate information to the farmers. This triggered a Rigor - Learning (RiLe2) sub cycle in which researchers reviewed the relevant literature to identify potential solutions to observed HCI issues.

\subsection{Second Physical Implementation of the Mobile Artefact}

As explained above we identified the importance of accurate, complete and up to date information. This triggered another round of Design - Heuristics Search (DeHS6) and Design - Functional Validation (DeFV2) sub cycles. In DeHS6 sub cycle, an ontology was developed to populate agriculture data to provide complete and accurate information to the farmers [39]. We also modified the user interfaces to display the additional information farmers needed.

In DeFV2 sub cycle, the research team tested the functional validation of the implemented system. At this stage GitHub was used to record the identified issues for the development team to rectify these.

The set of interfaces shown in Fig.12 was designed and partially implemented as a mobile web application. With the development of the Ontology we were able to provide information in context for the users. One example of this is to select the crops, based on the agro-zone corresponding to farm location. The main aim of these interfaces is to provide all required information to the farmers to make decisions at the crop planning stage of the farming life cycle.

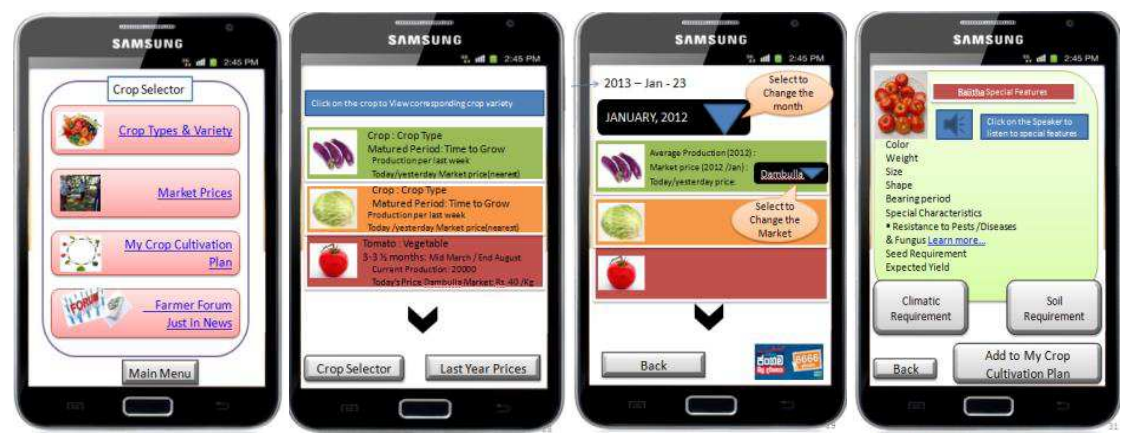

Fig. 12. Refined interfaces based on farmer feedback 
We conducted a Relevance - Validation Cycle (ReSV4) using the partially implanted web version and rest of the design as paper prototype. Using a sample of 50 farmers from two agro-zones in Sri Lanka, we tested the artefact for its suitability and usability. We observed the following during this validation.

- Functional requirements: We observed that farmers were able to provide their user requirements more easily and a meaningful way. As in the ReSV3 cycle in section 4.4, they continued to provide specific functional requirements that were not identified before.

- Usability issues: We observed several difficulties in using the mobile artefact by the farmers. Even with this new design, farmers face difficulties due to small button, image and font sizes. Sometimes, it took a while for a page to load and some had difficulties in understanding what was happening.

The feedback and observations generated enabled the research team to prioritise the findings. We choose usability as the first priority to increase the efficiency, effectiveness and the user satisfaction as now we have derived almost all the requirements for the crop planning stage.

\subsection{Deployed Version of the Mobile Artefact}

Prior to making any changes we went through a Rigour - Learning Cycle (RiLe3) to review HCI literature relating to identified issues. This led us to consider following aspects in refining the interfaces.

- Organisation of the functionalities in the Main Menu: We grouped the similar functions together while maintaining the important functions at the top of the menu.

- Navigation: We analysed the purpose of the back button. We minimised the use of back button to reduce the complexity of the design. We also considered ways to provide required information in minimum number of steps.

- Use of Colours: We used Itten colour theory; dark background and light font colours to visualise information efficiently. We used maximum of 6 colours to represent the menu items of the interface. We used same colour and/or similar shades when grouping the similar functionalities as shown in Fig. 13.

- Understand the user: most importantly since we are dealing with users new to the smart phone technology, we identified that it is very important to cater to the needs of these users. When analysing their capabilities based on the several field validations we identified the importance of leaving substantial amount of space between the touch items. From the experience we have gained from the validation of the mobile prototype, we have left a substantial amount of space between two buttons. When designing user input widgets we tried to minimize text inputs and provided many text boxes or drop down boxes instead. As shown in Fig. 14, when designing the login module, we used a separate cage for each digit and the cursor was moved to next cage automatically at the end of previous entry. This helped farmers to enter and delete the values with ease. 
Next we performed another Design Cycle; both Heuristic Search (DeHS7) and Functional Validation (DeFV3) to implement above mentioned changes and validate the new functionality by the research team. The interface design of the deployed version is shown in Fig. 15. This version is now deployed in two agro-regions in Sri Lanka. After we address the initial deployment issues, this application will become available to all farmers.

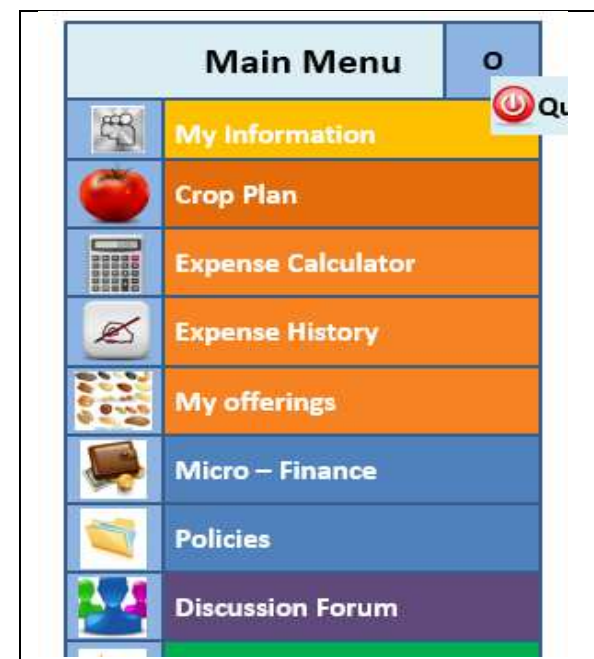

Fig. 13. Grouping of functionalities in the main menu using Itten colour theory

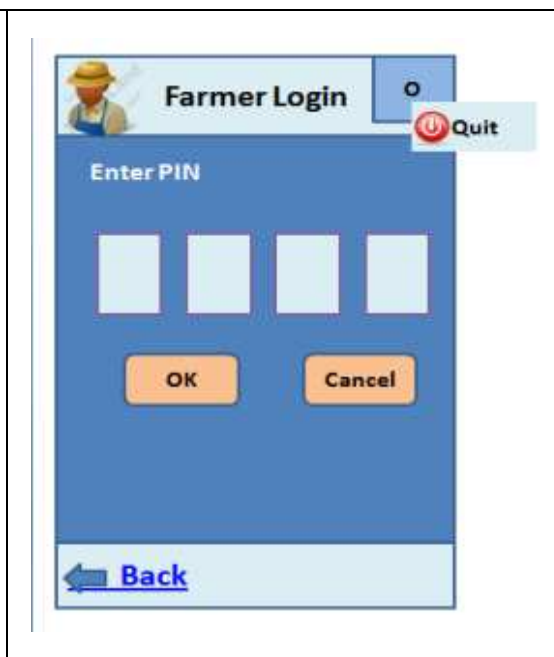

Fig. 14. One cage per digit in user inputs

\section{Conclusion}

In this project we designed a mobile based Information system to meet information needs of farmers at all stages of the farming life cycle. The design of the artefact was a challenge at the beginning due to several domain characteristics. ICT literacy of the farmers was very low. At the beginning they could not grasp the idea and specify their requirements. Researchers were unfamiliar with the complex agriculture domain. This added further barriers in identifying the important requirements. As a result, the system functionalities were not well defined at the beginning but they evolved over time. Secondly, farmers were new to the smart phones. Majority of them use basic feature mobile phones for communication purposes. Therefore, it was essential to present the information on smart phones in a way that is easy to find and use. As a result, the usability of the artefact was identified as an important aspect of this design.

Our research approach was guided by DSR methodology. Nature of the project made us to split the traditional 3 cycle model in to 6 cycles. Starting from a RePU1 we iterated among different sub cycles of DSR. The DSR Split model greatly assisted 
us in this project and we strongly recommend this model for any large and complex research project aiming to develop an artefact.

We started the project with some functional requirements derived from the initial surveys. At that stage we had very little knowledge about the user requirements. Even though the users were very familiar with the activities in their domain, they were not able to articulate the requirements at a sufficient level of detail. As a result, we developed scenarios to depict major activities in the domain. These scenarios helped us to better understand the problem domain and extract both functional and UI requirements. Initial sketching of the mobile interfaces further increased our knowledge on how to visualise the information on a mobile interface. Use of colour and presentation mechanisms derived from these sketches started to highlight the advantages of interplay between RE and HCI aspects. The split DSR model assisted us to effectively iterate among sub cycles focusing separately on RE and HCI aspects. As RE expertise were with researchers based in Sri Lanka and HCI expertise were with researchers based in Italy, this ability to separate concerns into different sub cycles greatly assisted us to manage the complexity of the design.

Based on feedback and new knowledge gathered, we made changes to the design of the artefact on an iterative basis. The artefacts were presented to the users sometimes as paper prototypes and other times as functional prototypes implemented on smart phones. This was done to minimize the implementation effort. This worked to our advantage in an unexpected way as users started to annotate the paper prototype to express their requirements. The feedback for these artefacts was obtained at different times from the farmers, field agriculture officers and fellow researchers. During our meetings with farmers we also conducted surveys to better identify farmer requirements. These field surveys and interviews helped us to bridge the gap in understanding the domain activities between the researchers and the users of the targeted domain. This led us to increase user participation and obtain better feedback about their needs. This further resulted in designing models such as causal map to better understand the behaviours that can be observed among stakeholders.

The methods such as paper prototyping enabled the researchers to collaborate more closely with the end users. This technique helped the farmers to feel and envisage the real artefact and be more specific on their needs. The physical implementation of the actual artefact was carried out by incorporating the feedback received from the users. As such, at the time of field validations using the actual mobile prototype, we observed that the farmers were familiar with the way we have implemented the basic requirements. This made farmers confident to specify more requirements in details.

Gradually the knowledge gained through these initial artefacts started to speed up the requirements identification process. At the initial stages we captured more of RE aspects, but in latter stages we started to identify more and more HCI needs. Through the approach that evolved we successfully overcame barriers that were encountered at the initial stages of the research. This experience highlights the need for blending both RE and HCI to better capture needs of the user and the usability issues.

Therefore, the process we used in creating these artefacts enabled the researchers to enrich both RE and $\mathrm{HCI}$ aspects; highlighting the importance of interplay between 
both RE and HCI when designing systems for masses especially if the technology as well as the system going to be new to them.
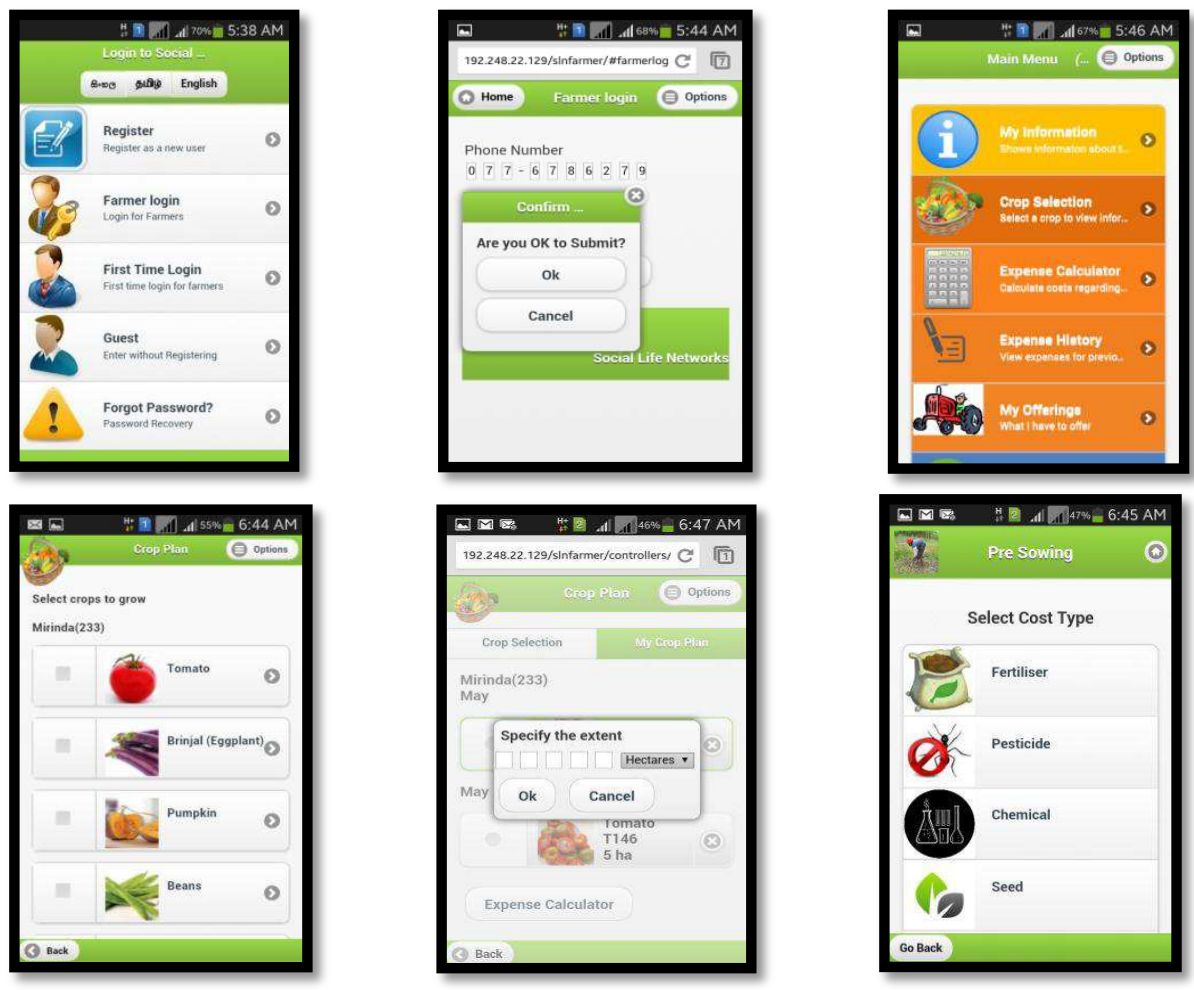

Fig. 15. Deployed version of the Mobile Artefact

\section{References}

[1] R. Jain and D. Sonnen, "Social Life Networks," IT Professional vol. 13, pp. 8 11, 2011.

[2] A. Ginige. (2011, 25/03/2012). Social Life Networks for the Middle of the Pyramid. Available: http://www.sln4mop.org//index.php/sln/articles/index/1/3

[3] V. K. Singh, M. Gao, and R. Jain, "Social pixels: genesis and evaluation," presented at the Proceedings of the international conference on Multimedia, Firenze, Italy, 2010.

[4] C. Z. Qiang, S. C. Kuek, A. Dymond, and S. Esselaar, "Mobile Applications for Agriculture and Rural Development," 2011. 
[5] T. Standage. (2009) Mobile Marvels. The Economist - A special report on telecoms in emerging markets.

[6] B. Sanou, "ICT Facts and Figurs," International Telecommunication Union2015.

[7] M.-S. Dao, S. Pongpaichet, L. Jalali, K. Kim, R. Jain, and K. Zettsu, "A Realtime Complex Event Discovery Platform for Cyber-Physical-Social Systems," in Proceedings of International Conference on Multimedia Retrieval, 2014, p. 201.

[8] H. Bandara, "Produce from the North creates surplus in veggies," in The Sunday Times, ed. Sri Lanka, 11 March 2012.

[9] S. Hettiarachchi, "N'Eliya carrot farmers in the dumps: Bumper harvest, but prices low," in The Sunday Times ed. Sri Lanka, 22 April 2012.

[10] S. Hettiarachchi, "Leeks Cultivators Desperate as Price Drops to Record Low," in Sunday Times, ed. Sri Lanka, 2011.

[11] Business Times, "Sri Lanka's vegetable supply exceeds demand," in Sunday Times, ed. Sri Lanka, April 22, 2012.

[12] C. Weerakkody, "Potato farmers mashed by imports," in The Sunday Times, ed. Sri Lanka: The Sunday Times, August 17, 2014.

[13] Shelton Hettiarachchi, "N. Eliya veggie farmers in dire straits," in The Sunday Times, ed. Sri Lanka: The Sunday Times, September 04, 2011.

[14] M. Rodrigo, "Desperate farmers seek help," in The Sunday Times, ed. Sri Lanka: The Sunday Times, September 16, 2012.

[15] G. Warushamana, "Oversupply hits big onion market," in Sunday Observer, ed. Sri Lanka, 2012.

[16] B. P. Kumara, "Goviyagen ganne thuttuwatalu eith appita ko labeta elavalu," in Divayina, ed: Lake House, 2011.

[17] L. Berenger, "Farmers strike veggie mafia," in The Sunday Times, ed. Sri Lanka, 2009.

[18] ISO, "ISO/IEC 25010:2011 - Systems and software engineering - Systems and software Quality Requirements and Evaluation (SQuaRE) - System and software quality models," 2011.

[19] T. Ginige and A. Ginige, "Towards next generation mobile applications for MOPS: investigating emerging patterns to derive future requirements," presented at the International Conference on Advances in ICT for Emerging Regions (ICTer), IEEE., Sri Lanka, 2011.

[20] I. Medhi, S. Patnaik, E. Brunskill, S. N. N. Gautama, W. Thies, and K. Toyama, "Designing mobile interfaces for novice and low-literacy users," ACM Trans. Comput.-Hum. Interact, vol. 18, p. 28, 2011.

[21] C. Danis, J. Ellis, W. Kellog, B. Hoefman, H. van Beijima, S. Daniels, et al., "Mobile phones for health education in the developing world: SMS as a user interface," presented at the ACM DEV, London, United Kingdom,, 2010.

[22] C. Putnam, E. Rose, R. Walton, and B. Kolko, "Mobile phone users in Kyrgyzstan: a case study of identifying user requirements for diverse users," presented at the Professional Communication Conference (IPCC), IEEE, 2009.

[23] N. Patel, S. Agarwal, N. Rajput, A. Nanavati, P. Dave, and T. S. Parikh, "Avaaj Otalo: A field study of an interactive voice forum for small farmers in rural India," in Human factors in computing systems USA, 2010, pp. 733-742. 
[24] B. V. Ratnam, P. Krishna Reddy, and G. S. Reddy, "eSagu 1: An IT based personalized agricultural extension system prototype - analysis of 51 Farmers' case studies," International Journal of Education and Development using Information and Communication Technology (IJEDICT), vol. 2, pp. 79-94, 2006.

[25] Pande A. K., Jagyasi B. G., and Jain R., "mKRISHI: A Mobile Multimedia Agro Advisory System for Remote Rural Farmers."

[26] Dialog Sri Lanka. (2010, November, 19). Dialog Trade Net. Available: http://www.tradenet.lk/

[27] Hector Kobbekaduwa Agrarian Research and Training Institute. (2014, November, 19). Mobitel Agri Price Information Index. Available: http://www.harti.gov.lk/index.php?option=com_content $\&$ view=article \&id=192\% 3Amobitel-agri-price-information-index\&catid=1\%3Alatest-from-harti\&lang=en

[28] H. A. S. S. Peter, "Communicating User Experience: "Wicked" Problems, Patchwork Personas, and the ICTD Project Lifecycle," Int. J. Sociotechnology Knowl. Dev., vol. 7, pp. 14-26, 2015.

[29] Y. Anokwa, T. N. Smyth, D. Ramachandran, J. Sherwani, Y. Schwartzman, R. Luk, et al., "Stories from the field: Reflections on HCI4D experiences," Information Technologies \& International Development, vol. 5, pp. pp. 101-116, 2009.

[30] A. R. Hevner, S. T. March, J. Park, and S. Ram, "Design Science in Information Systems Research," MIS Quarterly, vol. 28, pp. 75-105, 2004.

[31] S. T. March and V. C. Storey, "Design science in the information systems discipline: an introduction to the special issue on design science research," MIS Q., vol. 32, pp. 725-730, 2008.

[32] A. Hevner and S. Chatterjee, "Design Science Research in Information Systems," in Design Research in Information Systems. vol. 22, ed: Springer US, 2010, pp. 9-22.

[33] A. R. Hevner, "A Three Cycle View of Design Science Research," Scandinavian Journal of Information Systems, vol. 19, pp. 87-92, 2007.

[34] K. Peffers, T. Tuunanen, C. E. Gengler, M. Rossi, W. Hui, V. Virtanen, et al., "The design science research process: A model for producing and presenting information systems research," DESRIST, 2006.

[35] V. Vaishnavi and W. Kuechler. (2004). Design Science Reserach in Information Systems. Available: http://www.desrist.org/design-research-in-informationsystems/

[36] P. D. Giovanni, M. Romano, M. Sebillo, G. Tortora, G. Vitiello, L. D. Silva, et al., "User Centered Scenario based Approach for Developing Mobile Interfaces for Social Life Networks," presented at the 34th International Conference on Software Engineering (ICSE 2012) - UsARE Workshops, Zurich, Switzerland, 2012.

[37] L. De Silva, J. S. Goonethilake, G.N. Wickramanayake, and A. Ginige, "Towards using ICT to Enhance Flow of Information to aid Farmer Sustainability in Sri Lanka," presented at the Australasian Conference on Information Systems (ACIS), Geelong Australia, 2012. 
[38] S. Lokanathan and N. Kapugama. (2012, Smallholders and Micro-enterprises in Agriculture: Information needs \& communication patterns. 1-48. Available: http://lirneasia.net/projects/agriculture/

[39] A. I. Walisadeera, A. Ginige, and G. N. Wikramanayake, "User centered ontology for Sri Lankan farmers," Ecological Informatics, vol. 26, Part 2, pp. 140-150, 2015.

[40] L. N. C. De Silva, J. S. Goonetillake, G. N. Wikramanayake, and A. Ginige, "Farmer Response towards the Initial Agriculture Information Dissemination Mobile Prototype," in Computational Science and Its Applications - ICCSA 2013. vol. 7971, B. Murgante, S. Misra, M. Carlini, C. Torre, H.-Q. Nguyen, D. Taniar, et al., Eds., ed: Springer Berlin Heidelberg, 2013, pp. 264-278. 